\title{
ANALISIS PELAKSANAAN PROGRAM INDONESIA SEHAT DENGAN PENDEKATAN KELUARGA PADA INDIKATOR HIPERTENSI DI WILAYAH KERJA PUSKESMAS KABUPATEN BADUNG
}

\author{
Ida Ayu Putu Anggita Widya Swari*, Rina Listyowati \\ Program Studi Sarjana Kesehatan Masyarakat, Fakultas Kedokteran, Universitas Udayana
}

\begin{abstract}
ABSTRAK
Program Indonesia Sehat dengan Pendekatan Keluarga (PIS-PK) terdiri dari 12 indikator salah satunya adalah indikator penderita hipertensi berobat secara teratur. Kabupaten Badung sudah terindeks pra sehat namun menduduki peringkat kedua terendah capaian indikator hipertensi berobat secara teratur (24,52 \%) se Provinsi Bali. Tujuan penelitian untuk mengetahui pelaksanaan (PIS-PK) pada indikator hipertensi di wilayah kerja Puskesmas Kabupaten Badung khususnya dari segi input, proses dan lingkungan. Desain penelitian yang digunakan adalah penelitian deskriptif kualitatif. Penelitian dilaksanakan di Puskesmas Kuta II dan Mengwi III pada bulan Maret - Juli 2020. Jumlah informan 20 orang dipilih dengan purposive sampling. Pengumpulan data dengan wawancara mendalam dan $F G D$, kemudian dianalisis tematik. Validasi data dengan triangulasi sumber dan peer debriefing. Hasil penelitian yaitu input : SDM yang bertanggung jawab yaitu pemegang program hipertensi; tidak ada dana khusus untuk mendukung PIS-PK pada indikator hipertensi; Sarana prasarana pendukung berupa tensimeter, pinkesga dan alat tulis; metode berupa kunjungan keluarga; sasaran yaitu keluarga. Proses : Perencanaan berupa pembuatan tim dan jadwal tindak lanjut; Implementasi dilakukan dengan kunjungan, posbindu dan program inovasi; Monev melalui rapat minilok, pelaporan via aplikasi KS dan laporan bulanan. Lingkungan internal dan geografi tidak mempengaruhi program. Faktor ekonomi akan mempengaruhi gaya hidup masyarakat. Faktor sosial budaya mempengaruhi pelaksanaan program.
\end{abstract}

Kata Kunci: PIS-PK, Hipertensi, Puskesmas, Badung

\begin{abstract}
The Healthy Indonesia Program with the Family Approach (HIP-FA) consists of 12 indicators, such as an indicator of hypertension sufferers taking medical treatment regularly. Badung regency has indexed pre-healthy. Nevertheless, Badung Regency occupies the fourth position with the highest number of hypertension sufferers and ranks the second lowest achievement indicator of hypertension for regular treatment (24.52\%). This study aims to determine the implementation (HIP-FA) of hypertension indicators in Badung District Health Center, especially in terms of inputs, processes and outputs. The research design uses a qualitative descriptive study. The investigation takes place in Kuta II and Mengwi II Health Center from March - July 2020. The number of informants is 20 people that were selected through purposive sampling. The data was collected through in-depth interviews and FGD and analyze by thematic analysis. The data is validated by the triangulation of sources and peer debriefing. The research results which is the inputs: The HR responsible for the PIS-PK hypertension indicator is the holder of the hypertension program at the Public Health Center: There are no special funds to support PIS-PK on the hypertension indicators: Supporting equipment such as tensimeter, pinkesga and stationary: Method of family visit, the target is the family. Process: Planning in the form of team building and follow up schedule: The implementation is carried out by visiting Posbindu and innovation programs: M\&E is conducted once and every 3 months through minilok meetings and reporting via the KS application and monthly reports. The internal environment and geography do not affect the program. Economic factors do not affect the implementation of the program but will affect people's lifestyles. Socio-cultural factors influence the implementation of the program.
\end{abstract}

Keywords: HIP-FA, Hypertension, Primary Health Care, Badung

\section{PENDAHULUAN}

Saat ini Indonesia tengah menghadapi transisi epidemiologi yang menyebabkan pergeseran beban penyakit dari Penyakit
Menular ke Penyakit Tidak Menular (PTM). Pemerintah Indonesia telah berkomitmen dalam upaya pengendalian PTM. Salah satu program yang 
mendukung upaya tersebut adalah Program Indonesia Sehat Dengan Pendekatan Keluarga (PIS-PK). Puskesmas memiliki peranan yang sangat penting karena merupakan ujung tombak pelaksana program PIS-PK. Untuk menyatakan suatu keluarga tergolong kedalam keluarga sehat atau tidak digunakan sejumlah penanda atau indikator (Kemenkes RI, 2016a). Terdapat 12 Indikator yang dinilai pada program PISPK salah satunya penderita hipertensi berobat teratur.

Provinsi Bali telah melakukan PIS-PK secara bertahap sejak tahun 2016. Berdasarkan data rekapitulasi IKS per Kabupaten/Kota di Bali tahun 2019 tercatat bahwa IKS Provinsi Bali yaitu 0,36 dan berstatus tidak sehat per Oktober 2019. Selama program ini berlangsung, banyak kendala dan hambatan yang dihadapi dalam pelaksanaan dan pencapaian indikator pada program. Indikator penderita hipertensi berobat secara teratur memiliki capaian terendah di Provinsi Bali dengan capaian 27,78\%.

Hipertensi merupakan suatu keadaan meningkatnya tekanan darah sistolik $\geq 140$ $\mathrm{mmHg}$ dan diastolik $\geq 90 \mathrm{mmHg}$ pada dua kali pengukuran dengan selang waktu 5 menit dalam keadaan cukup istirahat (Kemenkes RI, 2014). Penelitian Widiyartha et al (2016) yang dilakukan di salah satu wilayah kerja Puskesmas Kabupaten Badung menyebutkan bahwa riwayat keluarga dengan hipertensi, stress, aktivitas fisik ringan, obesitas dan kebiasaan mengkonsumsi makanan asin berlebih merupakan faktor risiko terjadinya hipertensi. Hipertensi akan menyebabkan komplikasi pada beberapa organ tubuh jika penanganannya tidak tepat. Diantara 9 Kabupaten di Provinsi Bali, Kabupaten Badung merupakan Kabupaten yang menduduki posisi keempat jumlah penderita hipertensi terbanyak dengan jumlah kasus 81.570 orang.

Kabupaten Badung merupakan satu satunya Kabupaten di Bali yang telah terindeks pra sehat dengan IKS 0,53 per Oktober 2019. Walaupun demikian, masih banyak capaian indikator - indikator PISPK yang capaiannya masih rendah, salah satunya adalah indikator hipertensi. Kabupaten Badung menduduki peringkat kedua terendah capaian indikator penderita hipertensi berobat secara teratur (24,52 \%). Dari 13 Puskesmas di Kabupaten Badung, terdapat kesenjangan yang cukup tinggi yang terjadi pada capaian 12 Indikator PIS-PK khususnya pada capaian indikator hipertensi. Puskesmas dengan capaian indikator hipertensi tertinggi yaitu Puskesmas Mengwi III (58,64\%) dan capaian terendah yaitu Puskesmas Kuta II dengan 12\%.

Untuk itu penulis tertarik untuk melakukan penelitian dengan judul "Analisis Pelaksanaan Program Indonesia Sehat Dengan Pendekatan Keluarga pada Indikator Hipertensi di Wilayah Kerja Puskesmas Kabupaten Badung" untuk dapat melihat pengaruh dari input, proses dan lingkungan terhadap rendahnya capaian indikator hipertensi pada PIS-PK.

\section{METODE PENELITIAN}

Penelitian ini menggunakan desain penelitian kualitatif untuk menjelaskan pelaksanaan PIS-PK pada indikator hipertensi secara mendalam dan lengkap. 
Pengumpulan data dilakukan dengan metode wawancara mendalam dan Focus Group Discussion (FGD) kepada informan yang dipilih melalui metode purposive sampling. Informan sejumlah 20 orang yang dipilih berdasarkan azas kesesuaian dan kecukupan. Informan kunci yaitu Staff Seksi PKP Dinas, kepala Puskesmas Kuta II dan Mengwi III. Informan utama yaitu koordinator PISPK, koordinator program hipertensi, admin PISPK, petugas darbin di Puskesmas Kuta II dan Puskesmas Mengwi III. Informan tambahan yaitu 10 warga penderita hipertensi yang tinggal di wilayah kerja Puskesmas Kuta II dan Puskesmas Mengwi III. Instrumen pengumpulan data berupa daftar pertanyaan atau pedoman wawancara dan FGD. Penelitian dilaksanakan di Puskesmas Kuta II dan Puskesmas Mengwi III pada bulan Maret Juli 2020.

Pendekatan yang digunakan untuk menganalisis data yaitu dengan analisis tematik. Tahapan-tahapan analisis data yaitu sebagai berikut: pengumpulan data untuk dianalisis, transkripsi data, baca berulang, pengkodean data, pembuatan pola dari data yang sudah dipilih, penganalisaan data dan menampilkan hasil analisa. Strategi validasi data yang digunakan yaitu triangulasi sumber dengan membandingkan dan mengecek balik derajat kepercayaan suatu informasi yang diperoleh melalui sumber yang berbeda dan metode peer debriefing dengan dengan mendiskusikan penelitian dengan pembimbing. Penelitian ini telah diuji dan dinyatakan laik etik oleh Komisi Etik Penelitian Fakultas Kedokteran Universitas Udayana/Rumah Sakit Umum Pusat Sanglah Denpasar. Nomor kelaikan etik 2020.01.1.0389 tanggal 12 Mei 2019.

\section{HASIL}

Setelah dilakukan pengumpulan data dan analisis data, maka hasil penelitian pelaksanaan PIS-PK pada indikator hipertensi dapat dijabarkan sebagai berikut

\section{A. Karakteristik informan}

Karakteristik informan penelitian Berdasarkan tabel 1 didapatkan informasi bahwa mayoritas informan berjenis kelamin perempuan. Tingkat pendidikan informan beragam mulai dari SD hingga Pasca Sarjana. Umur informan berada di rentangan 24 - 63 tahun. Dari 20 informan, 1 berasal dari Dinas Kesehatan Kabupaten Badung, 4 informan berasal dari Puskesmas Kuta II dan 5 informan berasal dari Puskesmas Mengwi III. Terdapat 10 informan sebagai warga penderita hipertensi yang bertempat tinggal di wilayah kerja Puskesmas Kuta II dan Puskesmas Mengwi III. 
Tabel 1. Karakteristik Informan

\begin{tabular}{|c|c|c|c|}
\hline $\begin{array}{c}\text { Kode } \\
\text { Informan }\end{array}$ & Jenis Kelamin & Pendidikan & Status/Jabatan \\
\hline $\mathrm{I} 1$ & $\mathrm{P}$ & S1 & Admin PIS-PK Puskesmas Kuta II \\
\hline $\mathrm{I} 2$ & $\mathrm{P}$ & D3 & $\begin{array}{l}\text { Pemegang Program HT Puskesmas Kuta } \\
\text { II }\end{array}$ \\
\hline I3 & $\mathrm{P}$ & D3 & Koordinator PIS-PK Puskesmas Kuta II \\
\hline I4 & $\mathrm{P}$ & S2 & Kepala Puskesmas Kuta II \\
\hline I5 & $\mathrm{P}$ & D3 & $\begin{array}{l}\text { Koordinator PIS-PK Puskesmas Mengwi } \\
\text { III }\end{array}$ \\
\hline I6 & $\mathrm{P}$ & D3 & Petugas Bina Wilayah Desa Sempidi \\
\hline I7 & $\mathrm{P}$ & D3 & Admin PIS-PK Puskesmas Mengwi III \\
\hline I8 & $\mathrm{P}$ & D3 & $\begin{array}{l}\text { Pemegang Program HT Puskesmas } \\
\text { Mengwi III }\end{array}$ \\
\hline I9 & $\mathrm{L}$ & S1 & Kepala Puskesmas Mengwi III \\
\hline $\mathrm{I} 10$ & $\mathrm{P}$ & S1 & $\begin{array}{l}\text { Staff Seksi Pelayanan Kesehatan Primer } \\
\text { Dinas Kesehatan Kabupaten Badung }\end{array}$ \\
\hline F1 & $\mathrm{P}$ & SD & Warga \\
\hline F2 & $\mathrm{P}$ & SD & Warga \\
\hline F3 & $\mathrm{P}$ & SMA & Warga \\
\hline F4 & $\mathrm{L}$ & S1 & Warga \\
\hline F5 & $\mathrm{P}$ & S1 & Warga \\
\hline F6 & $\mathrm{L}$ & SMK & Warga \\
\hline F7 & $\mathrm{P}$ & SMP & Warga \\
\hline F8 & $\mathrm{P}$ & SD & Warga \\
\hline F9 & $\mathrm{P}$ & SMP & Warga \\
\hline F10 & $\mathrm{L}$ & SMK & Warga \\
\hline
\end{tabular}

\section{B. Input}

1) $\operatorname{SDM}($ man)

SDM yang ditugaskan untuk mengkoordinir pelaksanaan intervensi indikator hipertensi dalam PIS-PK yaitu pemegang program hipertensi di masing masing puskesmas. Pemegang program hipertensi Puskesmas Mengwi III dibantu oleh tim KBS dan pemegang program hipertensi Puskesmas Kuta II dibantu oleh pemegang program Perkesmas (Perawatan Kesehatan Masyarakat) dan tim KBS.
"Endak sih, cuman disini tuh emang ada pemegang program hipertensi PTM itu. Tapi untuk khusus buat PIS-PK indikator hipertensi sih ga ada." (I2)

Kinerja SDM dinilai sudah baik. Ketersediaan SDM di Puskesmas Kuta II untuk pelaksanaan intervensi lanjut dirasa cukup. Berbeda dengan Puskesmas Mengwi III, ketersediaan dirasa kurang untuk melaksanakan intervensi khusus indikator hipertensi karena hanya melibatkan pemegang program dan petugas KBS saja. Beban kerja juga akan 
dirasa tinggi karena banyaknya pekerjaan yang harus diselesaikan. Kendala lain dari segi kualitas SDM karena adanya petugas yang tidak sesuai kualifikasi.

"Nanti program itu dia sendiri yang mengelola. Inidah yang kewalahan kita untuk intervensinya." (I5)

"Gini, di satu bulan itu aku batasin misalnya 1 desa dulu, tapi kan itu belum selesai karena banjarnya banyak. Bisa 1 desa itu 2 - 3 bulanan lah mereka ngerjain." (I8)

"Yang jadi masalah itu ada beberapa tenaga yang memang tidak sesuai spesifikasinya." (I9)

2) Dana (money)

Berdasarkan hasil wawancara diketahui bahwa tidak ada dana khusus untuk indikator hipertensi, dana bersifat menyeluruh untuk seluruh kegiatan pada PIS-PK. Dana PIS-PK di puskesmas berasal dari dana BOK dan JKN. Alokasi anggaran untuk keperluan pendataan dan intervensi. Selama ini dana yang ada sudah cukup untuk mendukung pelaksanaan program pendataan dan intervensi awal. Namun pada Puskesmas Mengwi III dalam pengelolaannya terjadi kendala di awal karena pencairan dana terlambat. Selain itu di tahun 2020 tidak ada anggaran dana PIS-PK yang dipakai untuk intervensi lanjutan masing - masing indikator dalam program. Walaupun demikian kegiatan PIS-PK tetap bisa berjalan sebagaimana mestinya.

"Keseluruhan ya, ga ada dana khusus untuk indikator. Kecuali masing - masing program dia dapet dana lagi ya lain itu." (I10)

"Soalnya tahun 2020 hipertensi PISPKnya ga masuk BOK jadi ga dapet dana... Kan belum selesai intervensinya tapi dananya udah ga dapet" (I8)
3) Sarana (material)

Sarana yang digunakan untuk mendukung pelaksanaan intervensi indikator hipertensi yaitu tensimeter, pinkesga, dan alat tulis. Sarana tensi yang digunakan untuk pendataan maupun intervensi menggunakan milik puskesmas ataupun pustu. Dinkes Badung memberikan bantuan alat berupa posbindu kit. Kondisi sarana prasarana baik dan ketersediaannya cukup. Terdapat kendala dari segi sarana saat pendataan dan intervensi awal karena banyaknya tim yang harus turun lapangan namun ketersediaan alat terbatas.

"Sarananya.. tensi sama ATK, oh ya pinkesganya" (I7)

"Kita yang turun kan bisa sehari lebih dari 5. Kadang misalnya hari ini turun trus besoknya mau turun, temennya yang lain yang turun kan ga dapat alat jadinya" (I3)

4) Metode (method)

Metode yang digunakan dalam pelaksanaan PIS-PK yaitu kunjungan keluarga. Pendataan dan intervensi awal dilakukan oleh seluruh pegawai. Jika ditemukan suatu masalah hipertensi, maka petugas akan langsung memberikan intervensi berupa KIE atau memberikan rujukan untuk dibawa ke pelayanan kesehatan. Kunjungan keluarga dilaksanakan saat pagi dan sore. Setelah seluruh data hasil intervensi awal terkumpul maka data akan diberikan kepada pemegang program terkait untuk ditinjak lanjuti dalam pemberian intervensi lanjutan.

"Metodenya kunjungan rumah melalui pendekatan keluarga, pas kunjungan rumah dilakukan cek tensi trus diberikan informasi sesuai dengan permasalahan yang ada" (I5) 
"Jadi nanti masing - masing program yang merencanakan tindak lanjutnya seperti apa, ..." (I10)

Baik di Puskesmas Kuta II dan Puskesmas Mengwi III mengalami permasalahaan yang sama yaitu penolakan sering terjadi di awal kegiatan karena ada ketakutan masyarakat terhadap adanya isu penipuan. Permasalahan lain yaitu masyarakat sering tidak ada di rumah saat petugas melakukan kunjungan keluarga sehingga harus kunjungan berulang.

"Pertamanya memang dia menolak ... semua orang juga takut, Setelah itu dikasi penjelasan liatin SPT kita bahwa kita petugas puskesmas mau menerima."(I5)

\section{5) Sasaran (market)}

Sasaran program PIS-PK yaitu seluruh warga di kabupaten badung sesuai DO PIS-PK. Penderita hipertensi di Puskesmas Kuta II sejumlah 537 di dominasi lansia, sedangkan di Puskesmas Mengwi III sejumlah 1137 dari beragam usia. Pengetahuan masyarakat mengenai program PIS-PK kurang. Pengetahuan tentang penyakit hipertensi cukup dan diasumsikan meningkat setelah intervensi awal PIS-PK karena masyarakat sudah diberikan KIE.

"Rasanya kan setelah ada PIS-PK salah satunya ada KIE jadi kayaknya sih setelah ada PIS-PK sudah lebih meningkat dibandingkan sebelum PIS-PK." (I10)

Sikap perilaku masyarakat kebanyakan tidak berobat teratur karena tidak ada keluhan dan hanya berobat jika ada keluhan. Kesadaran masyarakat untuk mau melakukan perubahan perilaku sesuai dengan KIE yang diberikan petugas masih rendah. Alasan lain masyarakat tidak meminum obat teratur karena adanya ketakutan akan berefek samping Email Korespondensi : dayu.anggita@gmail.com pada kesehatan. Walaupun demikian tetapi masih banyak masyarakat yang sudah melakukan pengobatan teratur dengan kesadaran untuk ingin sembuh dan hidup nyaman.

"Menurut dia itu sudah minum obat sudah turun, apalagi kalau ga ada keluhan ga perlu minum obat lagi, seperti itu." (I5) "Untuk dia minum obat itu kesadarannya dia sendiri. Kadang - kadang kendala di hipertensi disitu, kesadarannya minum obat." (I10)

\section{Proses}

1) Perencanaan

Dalam perencanaan terhadap indikator hipertensi diawali dengan penyerahan data - data hipertensi hasil pendataan awal dari admin PIS-PK kepada pemegang program hipertensi. Pemegang program hipertensi akan menentukan langkah upaya intervensi lanjut berdasarkan data tersebut. Pelaksanaan perencanaan diawali dengan pembuatan jadwal dan penentuan target capaian, selanjutnya membagi tugas tim. Tidak ada kendala dalam perencanaan.

"Pembuatan jadwal... satu bulan di desa mana, targetnya berapa KK per hari. Jadi sekitar 2-3 bulan baru bisa selesai 1 desa."

\section{2) Pengimplementasian}

Puskesmas - puskesmas di Kabupaten Badung telah melakukan pendataan dan intervensi awal terhadap 100\% warganya sejak tahun 2019. Namun walaupun demikian berdasarkan hasil FGD yang dilakukan ke masyarakat penderita hipertensi menyatakan bahwa hanya sebagian responden mengaku pernah didatangi. Semua responden mengaku tidak ada penempelan stiker PIS-PK 
dirumahnya. Ada kemungkinan terjadi bias mengingat pendataan sudah dilakukan dari 3 tahun yang lalu dan ada kemungkinan responden tidak ada dirumah saat kegiatan tersebut dilakukan.

"Udah selesai survey 100\%. untuk kunjungan, dan pada saat itu juga langsung diintervensi awal." (I10)

"Mungkin kesini tapi saya ga ada, soalnya seringan kosong .. Takutnya kelewat gitu lo, kasian nanti dia udah berusaha tapi saya yang mungkin ga ada." (F4)

Berdasarkan data PIS-PK sebanyak 12\% pasien melakukan pengobatan teratur di Puskesmas Kuta II dan sebanyak 66,75\% pasien berobat teratur di Puskesmas Mengwi III. Intervensi lanjut pada indikator hipertensi di Puskesmas Kuta II dan Puskesmas Mengwi III dilakukan melalui kunjungan keluarga dan pelaksanaan program kesehatan yang terkait seperti posbindu dan program inovasi.

"Intervensi lanjutannya itu kan dia kalo yang sudah melakukan pengobatan ya dipantau aja." (I5)

"Hipertensi banyak kita sasar kegiatanya di kegiatan posbindunya." (I9)

Puskesmas Kuta II memiliki program inovasi SIKU KAWAN yang berarti Siap Kunjungi Keluarga Rawan. SIKU KAWAN merupakan wujud bekerjasama antar program hipertensi dengan program Perkesmas dimana kegiatannya berupa mengunjungi rumah - rumah penderita hipertensi untuk kontrol kesehatan, pemantauan meminum obat dan KIE.

"Misalnya ni ada pasien HT baru nanti nama dan alamat pasiennya kita serahin ke perkesmas, dan nanti perkesmas yang minta tolong ke ambulan desa atau perawat desa untuk kunjungi pasien ke rumahnya. Yaa kayak jemput bola." (I2) Puskesmas Mengwi III memiliki program inovasi untuk meningkatkan capaian indikator hipertensi yaitu dengan melakukan SEHAT AKTIF yang berarti Usia Produktif Sadar Kesehatan. Program ini dilaksanakan dengan melakukan pelayanan kesehatan di kantor lurah. Pengecekan kesehatan tidak hanya mengenai cek tensi saja, melainkan ada layanan lain seperti cek gula darah, asam urat dan kolesterol.

"Itu kita kerjasama sama lurah jadi kayak sistemnya ketok pintu minta tolong sama lurah, kita yang dateng ke kantor lurah nanti lurah yang manggil masyarakatnya kesana." (I8)

Kendala yang dirasakan Puskesmas Mengwi III saat pelaksanaan intervensi PIS-PK khususnya pada indikator hipertensi yaitu minimnya tenaga untuk melaksanakan intervensi lanjutan karena hanya pemegang program dan petugas KBS, sehingga petugas kewalahan dan capaian tidak optimal akibat perlu waktu yang lama untuk mengintervensi seluruh sasaran.

"Hipertensi khusus sendiri dia, pemegang program sama gini (KBS) aja. Sedangkan kan kasus hipertensi itu kan banyak, waktu kunjungan rumah untuk intervensi lanjut dia sendiri. Pada saat ada posbindu, posyandu, kan ada posbindunya itu.. lewat itudah dia melakukan intervensinya dia."(I5)

Kendala lainnya yaitu Definisi Operasional (DO) hipertensi yang ambigu sehingga angka hipertensi tinggi. Petugas lapangan bingung untuk menentukan kapan masyarakat dikatakan teratur minum obat mengingat tidak ada acuan yang pasti untuk indikator keteraturan 
yang dimaksud. Hal ini yang menyebabkan peningkatan kasus secara signifikan pada penderita hipertensi yang tidak berobat.

"Indikator kita kan penderita HT yang melakukan pengobatan teratur, jadi sangat sulit menentukan karena luas sekali kann.. teratur tu apakah setiap hari atau apa.". (I10)

3) Monitoring dan Evaluasi

Monitoring dan evaluasi dilaksanakan melalui lokmin bulanan, sedangkan monev lintas sektor melalui lokmin 3 bulanan. Monev ini dilakukan untuk meninjau proses kegiatan yang sudah berjalan serta hasil kegiatan dalam mengidentifikasi hambatan dari yang sudah direncanakan. Pemegang program hipertensi akan menyampaikan data pasien yang telah diintervensi lanjut ke admin PIS-PK, kemudian admin akan mengubah data di aplikasi, data progress tersebut yang dibahas saat monev. Dinas kesehatan kabupaten dan provinsi juga melaksanakan monev ke tiap Puskesmas untuk memastikan apakah pelaksanaannya sudah sesuai pedoman dan DO yang ada.

"Kita biasanya monev tiap bulan sih kayak rapat bulanan atau mini lokmin. Kalau memang ada permasalahan ya pasti kita bahas disana." (I2)

Pelaporan dilakukan melalui aplikasi keluarga sehat dan laporan bulanan yang diberikan ke dinas kabupaten sesuai dengan format yang ada. Kendala dalam pelaporan yaitu aplikasi keluarga sehat sering error sehingga menghambat proses update data. Berdasarkan wawancara dengan staff dinas kesehatan, sejak awal tahun 2020 data capaian tidak berubah.
Tidak berubahnya hasil capaian mungkin diakibatkan karena pihak puskesamas belum update data di aplikasi atau terjadi kesalahan pada sistem.

"Cuman dari tahun 2020 ini kayaknya aplikasinya agak hang ya. Soalnya tak liat capaiannya kok tetep dari bulan desember sampai sekarang." (I10)

"Capaian rendah itu karena data awal PIS-PK belum dirubah, karena kan aplikasi sempat error jadinya ngerubah data itu kenaikan datanya kecil jadinya." (I1).

\section{Lingkungan}

1) Lingkungan Internal

Secara manajerial pembagian tugas diatur oleh pemegang program dan semua staff terkait mau melaksanakan. Tingkat manajerial bisa menghambat jika perencanaan program tidak baik, adanya perbedaan data antar program, dan adanya konflik internal. Tapi walaupun ada permasalahan - permasalahan kecil dari segi manajerial tidak terdampak pada pelaksanaan program secara keseluruhan.

"Kalau konflik internal pasti ada, Semua staff punya kepentinganya sendiri, tapi sejauh niki bisa kita komunikasikan dan memang ada yang harus mengalah." (I9)

Puskesmas melakukan strategi berupa perencanaan terintegrasi yang menghubungkan keunggulan strategis puskesmas dengan tantangan lingkungan luar yang ada. Strategi yang dilakuan oleh puskesmas yaitu pengumpulan data yang lebih akurat, saling koordinasi dan melakukan pembagian tugas dengan baik. Aspek strategis membantu pelaksanaan PIS-PK khususnya di indikator hipertensi.

"Kalo menghambat sih engga, karena kayak tadi kan strateginya kita harus koordinasi dulu sama pemegang program" (I10) 
2) Lingkungan Eksternal

Faktor ekonomi masyarakat seharusnya tidak menghambat dalam mengakses pengobatan hipertensi karena di Kabupaten Badung masyarakat sudah mempunyai jaminan Krama Badung Sehat (KBS) yang dapat dipergunakan untuk mengakses pelayanan kesehatan secara gratis. Seluruh responden FGD menyebutkan memiliki jaminan kesehatan dan mengakses pelayanan dengan JKN KIS atau KBS.

"Engga sih ya, soalnya kan warga sudah punya jaminan kesehatan, jadi bisa digunakan untuk berobat secara gratis karena adanya KBS" (I4)

Faktor ekonomi lebih berdampak pada gaya hidup masyarakat untuk memicu hipertensi. Seseorang yang memiliki kondisi ekonomi menengah kebawah cenderung lebih tidak patuh terhadap diet hipertensi yang dianjurkan oleh petugas kesehatan. Faktor ekonomi juga dapat memicu stress yang akan berdampak pada peningkatan tekanan darah. Masyarakat dengan tingkat ekonomi rendah cenderung memiliki beban pikiran mengenai keuangan sehingga menimbulkan stress.

“(ekonomi) Ada pengaruhnya ke HT karena itu kan berhubungan dengan gaya hidup." (I10)

Faktor geografi tidak menghambat pelaksanaan PIS-PK khususnya pada indikator hipertensi di Puskesmas Kuta II dan Puskesmas Mengwi III. Hal ini dikarenakan kondisi geografis wilayah yang datar diwilayah perkotaan sehingga akses jalan baik dan pola pemukiman tidak menyebar.
"Kalau geografi, di wilayah kerja kami tidak begitu, karena kita juga semua wilayah terjangkau dengan kendaraan... Rasanya dari segi geografis sih tidak.(I9) Faktor sosial budaya dapat mempengaruhi pelaksanaan PIS-PK khususnya pada indikator hipertensi di Kabupaten Badung. Faktor - faktor yang mempengaruhi yaitu pola aktivitas masyarakat yang tinggi. Selain itu di Puskesmas Kuta II dan Puskesmas Mengwi III termasuk puskesmas kawasan perkotaan dimana karakterisik masyarakatnya cenderung individualis dan bersifat tertutup sehingga intervensi lebih sulit dilakukan.

"Kalo di kota itu kan sudah dia jarang bersosialisasi, jadi lebih cuek jadinya." (I10)

Tradisi dan adat budaya tidak mempengaruhi pelaksanaan program. Walaupun ada upacara adat atau rahinan suci keagamaan, masyarakat tetap bisa melakukan pengobatan. Petugas puskesmas dapat melakukan penjadwalan ulang jika kegiatan berbenturan dengan upacara adat.

"Kalo sibuk mungkin bisa koordinasi jadwal aja. Misalkan pas itu ada acara ngaben kita ga bisa kesana ya ga usah kesana, ganti jadwal gitu" (I7)

Tradisi dan adat secara tidak langsung akan mempengaruhi pola konsumsi masyarakat. Adanya tradisi untuk menyuguhkan makanan tradisional pada upacara keagamaan akan mempengaruhi kejadian hipertensi karena masyarakat akan disuguhkan makanan terbuat dari daging - dagingan yang tinggi kolesterol dan garam. Selain itu adanya jamuan rokok saat berlangsungnya hajatan juga akan mempengaruhi kejadian hipertensi, mengingat merokok adalah salah satu faktor risiko hipertensi. 
"Mungkin kalo tradisi yang namanya ada di Bali kan ada aja yang namanya ngelawar, atau apa.. itu kan juga bisa, ada daging - daging yang bisa meningkatkan ini (HT) kan" (I3)

\section{DISKUSI}

\section{1) Input PIS-PK pada indikator hipertensi}

SDM yang ditugaskan untuk mengkoordinir pelaksanaan PIS-PK pada indikator hipertensi yaitu pemegang program hipertensi dan dibantu oleh tim KBS. Ketersediaan SDM di Puskesmas Mengwi III masih dirasa kurang untuk intervensi lanjut PIS-PK khususnya di indikator hipertensi. Kurangnya SDM menyebabkan pelaksanaan intervensi hipertensi menjadi lama dan tidak selesai tepat waktu sesuai dengan target yang ditetapkan. Tim KBS tidak hanya membantu dalam intervensi pada indikator hipertensi saja, melainkan membantu indikator - indikator lain juga dalam PIS-PK sehingga jam kerja panjang. Banyaknya pekerjaan yang ditugaskan dan lamanya jam kerja tentu akan menyebabkan peningkatan beban kerja yang berdampak pada kelelahan kerja dan stress kerja. Penelitian Sarda (2018) dan Kasmarani (2012) menyebutkan bahwa beban kerja akan berpengaruh positif terhadap dan signifikan terhadap kelelahan kerja dan stress kerja. Menurut Setyawati (2010) menyebutkan bahwa kelelahan kerja dapat menyebabkan prestasi kerja menurun karena adanya penurunan semangat dan produktivitas.

Berdasarkan hasil penelitian, kinerja SDM baik walaupun beban kerja tinggi. Hal ini mungkin terjadi karena seluruh petugas memberikan performa yang maksimal untuk menjalankan program, sudah mendapat pelatihan, serta terjalinnya koordinasi dan kerjasama yang baik antar petugas di puskesmas. Tidak berpengaruhnya beban kerja terhadap kinerja sejalan dengan penelitian (Sitepu, 2013). Pengaruh pelatihan terhadap kinerja dijelaskan oleh Gile et al., (2018) dimana pelatihan dapat meningkatkan kinerja tim. Permasalahan lain dari segi SDM yaitu dari segi kualitas SDM karena ada yang tidak sesuai kualifikasi sehingga akan mempengaruhi hasil dari pekerjaan tersebut. Dibutuhkan pelatihan dan pendampingan terhadap SDM yang tidak sesuai kualifikasi agar performa kerja meningkat.

Dana merupakan modal operasional bagi suatu program. Tidak ada dana khusus untuk indikator hipertensi, dana bersifat menyeluruh untuk seluruh kegiatan pada PIS-PK. Pelaksanaaan intervensi lanjut dianggarkan oleh masing - masing program yang terkait. Perencanaan dan pengalokasian anggaran yang baik sangat penting dilakukan karena dapat berdampak terhadap pelaksanaan program secara keseluruhan. Jika tidak ada dana maka pelaksanaan program dapat terhambat dan berpengaruh pada kinerja pegawai. Tidak adanya dana insentif yang diberikan pada petugas untuk melakukan kunjungan keluarga sedikitnya akan berpengaruh terhadap kinerja petugas yang kurang optimal. Hal ini sesuai dengan penelitian Pratiwi et al (2017) dan Munandar et al., (2014) yang menjelaskan bahwa ketersediaan anggaran berpengaruh secara tidak langsung terhadap kualitas pelayanan kesehatan melalui kinerja 
pegawai karena tidak adanya insentif yang bisa memacu motivasi karyawan untuk meningkatkan kualitas kerjanya.

Sarana prasarana diperlukan sebagai media pelaksana fungsi - fungsi dari manajemen untuk mencapai tujuan (Amirullah, 2015). Sarana penunjuang berupa tensimeter, pinskesga, alat tulis. Agar tensimeter tersebut selalu dalam kondisi baik maka harus dilakukan pemeliharaan dan kalibrasi. Permasalahan dari segi sarana terjadi saat kegiatan pendataan dan intervensi awal. Permasalahan tersebut disebabkan karena jumlah alat yang tersedia tidak sesuai dengan banyaknya tim yang melakukan kunjungan. Manajemen perlengkapan yang baik diperlukan untuk mendukung pelaksanaan program.

Dalam mencapai tujuan program perlu menggunakan metode yang harus disesuaikan dengan perencanaan yang sudah dibuat agar metode tersebut tepat sasaran (Amirullah, 2015). Metode yang digunakan dalam PIS-PK pada indikator hipertensi yaitu kunjungan keluarga. Metode kunjungan keluarga telah dilaksanakan sesuai dengan pedoman yang ada. Permasalahan sering ditemui seperti keluarga tidak ada dirumah saat dikunjungi. Petugas diharuskan untuk melakukan kunjungan berulang - ulang agar dapat bertemu dengan sasaran, dan tidak efisien secara waktu. Penolakan terjadi karena ketidaktahuan masyarakat terkait program dan adanya ketakutan masyarakat untuk menerima orang asing karena isu kriminal yang terjadi. Penolakan juga terjadi pada pelaksanaan PIS-PK dibeberapa puskesmas seperti di Puskesmas Mulyaharja (Fauzan, et al.,
2019) dan di Puskesmas Kubu II (Adiartha, 2019). Mengatasi permasalahan dari segi metode perlu kerjasama dengan lintas sektor untuk membantu mengatasi penolakan warga. Pelibatan lintas sektor dalam upaya mengatasi hambatan PIS-PK juga dilakukan pada penelitian Agni (2018).

Sasaran dari PIS-PK yaitu keluarga. Penerimaan masyarakat terhadap program tergolong baik walaupun terjadi beberapa penolakan di awal. Pengetahuan masyarakat mengenai PIS-PK kurang. Pengetahuan masyarakat mengenai hipertensi lebih baik setelah adanya program PIS-PK. Tingkat pengetahuan pasien akan mempengaruhi kepatuhan pasien hipertensi dalam menjalankan pengobatannya. Penelitian Ekarini (2011) yang menyebutkan bahwa adanya hubungan yang sangat bermakna antara tingkat pengetahuan dengan tingkat kepatuhan klien hipertensi dalam menjalankan pengobatan. Penelitian Nia et al., (2018) menyebutkan penyuluhan kesehatan tentang hipertensi berpengaruh terhadap peningkatan pengetahuan tentang penyakit. Sehingga berdasarkan hal tersebut, puskesmas perlu melakukan upaya untuk meningkatkan pengetahuan pasien hipertensi dengan mengadakan penyuluhan dengan memperhitungkan sarana komunikasi yang tepat guna dan tingkat pendidikan sasaran untuk meningkatkan kepatuhan dalam meminum obat antihipertensi.

Sikap dan perilaku individu akan mempengaruhi kepatuhan pengobatan hipertensi yang dijalani. Perilaku perilaku tersebut berkaitan dengan motivasi. Motivasi yang tinggi dapat 
terbentuk karena adanya hubungan antara kebutuhan, dorongan dan tujuan. (Ekarini, 2011). Masyarakat tidak patuh meminum obat - obatan secara teratur karena keyakinan akan berefek buruk pada organ tubuh. Keyakinan ini menyebabkan pasien cenderung untuk mencari jalan alternatif untuk mengatasi penyakitnya. Dapat disimpulkan bahwa keyakinan serta budaya ikut menentukan perilaku kepatuhan. Kepatuhan akan semakin baik jika seseorang memiliki keyakinan bahwa anjuran kesehatan itu dianggap benar (Wahyudi et al., 2017).

\section{2) Proses PIS-PK pada indikator hipertensi}

Perencanaan PIS-PK pada indikator hipertensi dilaksanakan setelah didapatkan data dan intervensi awal. Perencanaan diserahkan ke pemegang program hipertensi untuk kemudian ditetapkan upaya intervensi lanjut yang sesuai dan tepat sasaran. Tahapan perencanaan yang dilakukan telah sesuai dengan Permenkes RI No. 44 Tahun 2016 tentang Pedoman Manajemen Puskesmas. Perencanaan dapat dilaksanakan secara terintegrasi baik lintas program maupun lintas sektor.

Setelah perencanaan selesai maka dilanjutkan dengan proses pengimplementasian. Implementasi program akan berjalan baik apabila manajemen puskesmas baik dan didukung oleh perencanaan yang matang serta penyediaan input yang sesuai kebutuhan (Adiartha, 2019). Implementasi PIS-PK dilaksanakan sesuai dengan rencana. Puskesmas - puskesmas di Kabupaten Badung telah melakukan pendataan dan intervensi awal terhadap $100 \%$ warganya sejak tahun 2019. Klaim $100 \%$ tersebut menjadi dipertanyakan mengingat tidak semua informan FGD mengaku sudah didata. Puskesmas diharapkan melakukan verifikasi data kembali ke lapangan agar data yang ada menjadi valid. Sistematika verifikasi telah diatur pada buku pedoman monev pelaksanaan PIS-PK, dimana verifikasi di tingkat puskesmas dilakukan pada $10 \mathrm{KK}$ (secara acak) setiap desa atau kelurahan (Kemenkes RI, 2017).

Intervensi lanjut pada indikator hipertensi di Puskesmas Kuta II dan Puskesmas Mengwi III dilakukan melalui kunjungan keluarga, posbindu PTM dan program inovasi. Pelaksanaan intervensi ini sudah sesuai dengan petunjuk teknis penguatan manajemen puskesmas dengan pendekatan keluarga, dimana intervensi diarahkan pada UKP (intervensi terhadap hipertensi dengan kunjungan pasien) dan UKM puskesmas (intervensi melalui posbindu) (Kemenkes RI, 2016d). Petugas - petugas di kedua puskesmas memonitoring kondisi kesehatan dan keteraturan meminum obat penderita hipertensi. Bukti pasien sudah berobat teratur yaitu dengan melihatkan ketersediaan obat. Selain kunjungan keluarga, kedua puskesmas melakukan intervensi indikator hipertensi di Posbindu PTM. Pasien akan diarahkan untuk mengunjungi Posbindu tiap bulannya untuk memeriksakan hipertensinya.

Selain pelayanan posbindu PTM, puskesmas berupaya untuk meningkatkan capaian indikator hipertensi pada PIS-PK dengan menciptakan suatu program 
inovasi yang disesuaikan dengan kemampuan puskesmas dan kondisi sasaran di wilayah kerja. Puskesmas Kuta II membuat program inovasi SIKU KAWAN dimana puskesmas akan melakukan kunjungan untuk memberikan pelayanan kesehatan atau menjemput pasien untuk dibawa ke puskesmas. Layanan ini tercetus karena adanya pasien yang tidak bisa mendatangi puskesmas karena kesibukan anggota keluarga. Berkaca pada hal tersebut, pemberian penyuluhan pada keluarga pasien dirasa perlu karena keluarga merupakan lembaga terkecil dari masyarakat. Keluarga harus berdaya dalam melakukan pendampingan terutama dalam pendampingan meminum obat. Hal ini sejalan dengan penelitian Dewi et al., (2017) yang menyebutkan bahwa terdapat hubungan yang bermakna antara fungsi keluarga dengan self care lansia, dan penelitian dari Matheos et al., (2018) yang menyebutkan bahwa keluarga berperan merawat pasien hipertensi dalam hal mengontrol gaya hidup, memberikan peran sebagai penyedia, merawat anggota keluarga yang sakit, dan memberikan informasi mengenai penyakit hipertensi.

Puskesmas Mengwi III membuat program inovasi SEHAT AKTIF. Program ini dilaksanakan dengan melakukan pelayanan kesehatan di kantor lurah sebagai upaya perluasan penjangkauan intervensi pada penderita hipertensi. Kegiatan SEHAT AKTIF ini bergantung pada pelibatkan lintas sektor sebagai penentu faktor keberhasilan program tersebut. Berdasarkan penelitian Laelasari et al. (2019) menyebutkan bahwa kepemimpinan lokal akan mempengaruhi peningkatan kesadaran masyarakat. Kepemimpinan merupakan salah satu kunci keberhasilan intervensi. Pendapat ini sejalan dengan pelaksanaan program SEHAT AKTIF yang terjadi di Puskesmas Mengwi III, dimana masyarakat mau untuk berpartisipasi dan datang dalam kegiatan tersebut berkat adanya integrasi antar puskesmas dan aparatur desa.

Dalam pengimplementasian PIS-PK pada indikator hipertensi tentunya ditemukan berbagai kendala dan permasalahan. Kendala utama pelaksanaan implementasi PIS-PK pada indikator hipertensi berada pada definisi operasional hipertensi yang ambigu sehingga angka kasus menjadi tinggi. Menindaklanjuti kendala tersebut, puskesmas melakukan pelaporan berjenjang. Dinas Kesehatan Kabupaten Badung kemudian mengadakan rapat untuk membahas mengenai kendala tersebut, didapatkan hasil berupa surat rekomendasi No. 440/1499/VII/Diskes yang mengatur standar dalam penetapan DO hipertensi PIS-PK. Pembuatan surat rekomendasi ini sesuai dengan peran dinas kesehatan kabupaten yang diatur dalam Permenkes No. 39 Tahun 2016 yang menjelaskan bawa salah satu peran dinas kesehatan kabupaten/kota yaitu koordinasi dan bimbingan. Peran ini mengharuskan dinas untuk memberikan bimbingan dan membantu dalam memecahkan masalah - masalah yang dihadapi puskesmas (Kemenkes RI, 2016b).

Setelah program dilaksanakan, maka proses selanjutnya yaitu melakukan monitoring dan evaluasi. Kegiatan monev telah rutin dilaksanakan oleh Dinas 
Kesehatan dan Puskesmas. Monev Indikator hipertensi pada PIS-PK dilakukan bersamaan dengan monev PISPK. Kegiatan monev dilakukan sebulan sekali melalui lokakarya mini bulanan dan lokakarya mini lintas sektor tiga bulanan puskesmas membahas mengenai permasalahan yang terjadi, penentuan tindakan koreksi, dan progress capaian program. Teknis monev indikator hipertensi yaitu pemegang program hipertensi akan melaporkan progres intervensi, selanjutnya hasil perubahan data tersebut kemudian dipergunakan untuk mempertimbangkan upaya tindak lanjut. Langkah - langkah tersebut sudah sesuai dengan petunjuk teknis pengawasan, pengendalian, dan penilaian (P3) PIS-PK pada puskemas (Kemenkes RI, 2016e). Monev dilaksanakan baik dari internal maupun eksternal. Monev internal dilaksanakan oleh kepala puskesmas, tim PIS-PK, dan penanggung jawab program terkait. Sedangkan monev dilaksanakan oleh Dinkes Provinsi dan Dinkes Kabupaten. Monev oleh dinas telah sesuai dengan perannya yang telah diatur oleh Permenkes No. 39 Tahun 2016 untuk melakukan pemantauan dan pengendalian.

Pelaporan dilakukan setiap bulan melalui aplikasi keluarga sehat dan laporan tertulis yang dikirimkan ke dinas kabupaten. Format laporan mengikuti format laporan yang diberikan oleh dinas kabupaten. Permasalahan dari segi pelaporan di Puskesmas Kuta II dan Puskesmas Mengwi III yaitu aplikasi keluarga sehat sering error sehingga menghambat proses update data dan berpengaruh terhadap data capaian program. Sejak Desember 2019 progres capaian IKS dan capaian per indikator tidak mengalami perubahan. Hal ini dapat dipengaruhi oleh dua hal yaitu terjadinya kesalahan sistem yang mengakibatkan sistem tidak dapat menerjemahkan data yang telah diinput, atau dikarenakan petugas admin PIS-PK puskesmas belum melakukan perubahan data karena seringnya error tersebut menyebabkan beberapa petugas malas untuk mengupdate data. Kepuasan pengguna memengaruhi minat seseorang untuk menggunakan sistem yang selanjutnya akan mempengaruhi persepsi kemanfaatan yang dirasakan oleh pengguna. Rasa tidak puas pengguna terhadap suatu sistem akan mempengaruhi rasa malas petugas untuk memanfaatkan sistem aplikasi KS. Pengaruh kepuasan pengguna terhadap minat menggunakan dan persepsi manfaat dijelaskan pada penelitian yang dilakukan oleh Ekowati et al., (2019). Puskesmas harus melakukan pengecekan manual antar data aplikasi dengan data riil.

\section{3) Lingkungan PIS-PK pada indikator hipertensi}

Lingkungan dapat mempengaruhi sistem. Dari segi lingkungan internal, puskesmas memerlukan pengorganisasian agar tujuan dari pelaksanaan PIS-PK dapat tercapai. Secara manajerial pembagian tugas diatur oleh pemegang program dan semua staff terkait secara sukarela bersedia melaksanakan. Aspek manajerial di kedua puskesmas tidak terlalu menghambat pelaksanaan program karena suasana kerja baik dan permasalahan yang terjadi dapat 
diselesaikan dengan baik. Aspek manajerial dapat menghambat program apabila langkah perencanaan tidak baik. Perencanaan di puskesmas akan mengacu pada data - data register puskesmas. Adanya perbedaan data antara program satu dengan program lainnya akan mempengaruhi langkah perencanaan yang dilakukan karena sumber acuannya tidak valid. Hal yang mempengaruhi aspek manajerial lainnya yaitu adanya konflik yang terjadi di lingkungan internal puskesmas. Kemampuan manajemen konflik sangat dibutuhkan di puskesmas untuk menanggulangi konflik yang ada. Apabila konflik kerja meningkat maka akan menurunkan kepuasan kerja dan berpengaruh pada penurunan kinerja karyawan (Laura, 2019).

\begin{tabular}{ccc} 
Aspek & strategis & \multicolumn{2}{c}{ mendukung } \\
pelaksanaan & program & PIS-PK pada \\
indikator & hipertensi & Puskesmas
\end{tabular}
melakukan strategi berupa pengumpulan data yang lebih akurat, saling koordinasi lintas program dan lintas sektor, serta pengembangan program inovasi. Aspek strategis ini perlu untuk dievaluasi secara berkala karena lingkungan internal dan eksternal organisasi bersifat dinamis sehingga butuh penyesuaian penyesuaian strategi. Penilaian terhadap tantangan dan ancaman dari lingkungan eksternal dan kelemahan kelebihan dari faktor internal dapat dilakukan dengan analisis SWOT

Lingkungan eksternal terdiri dari aspek ekonomi, geografi, dan sosial budaya. Berdasarkan hasil FGD diketahui bahwa seluruh informan memiliki sudah memiliki jaminan kesehatan dan mengakses pelayanan dengan JKN KIS atau KBS. Dengan adanya jaminan kesehatan masyarakat seharusnya tidak kesulitan dalam memanfaatkan fasilitas kesehatan untuk melakukan pengobatan secara teratur dengan gratis. Penyataan ini sejalan dengan Purnamaningrum (2010) yang menyebutkan bahwa seseorang yang memiliki asuransi kesehatan lebih sering memeriksakan kesehatan ke dokter karena telah dijamin sepenuhnya oleh pihak asuransi. Faktor ekonomi akan berdampak pada pada gaya hidup masyarakat untuk memicu hipertensi. Seseorang yang memiliki keterbatasan ekonomi akan mengonsumsi makanan yang sesuai dengan standar keuangan yang mereka miliki dan mengabaikan anjuran dokter. Selain itu masyarakat dengan tingkat ekonomi rendah cenderung memiliki beban pikiran mengenai masalah keuangan sehingga menimbulkan stress. Penyataan mengenai pengaruh faktor ekonomi terhadap hipertensi sesuai dengan hasil penelitian Miyuslianu \& Yunita (2011) menyebutkan seseorang yang memiliki kondisi ekonomi menengah kebawah berisiko 2,4 kali untuk tidak patuh terhadap diet hipertensi, dan penelitian dari Andria (2013) yang menyebutkan bahwa faktor ekonomi dapat memicu stres yang akan berdampak pada peningkatan tekanan darah.

Kondisi geografi tidak mempengaruhi pelaksanaan program karena kondisi geografis berada diwilayah perkotaan sehingga relief wilayah datar dan akses jalan baik. Dengan kondisi geografi tersebut, petugas kesehatan akan mudah menjangkau masyarakat untuk melakukan intervensi, selain itu masyarakat juga mudah untuk menjangkau layanan 
kesehatan. Hasil penelitian ini tak sejalan dengan hasil penelitian dari Adiartha, (2019) yang menyebutkan bahwa faktor geografi dapat mempengaruhi pelaksanaan PIS-PK di Puskesmas Kubu II.

Faktor sosial budaya dapat mempengaruhi pelaksanaan PIS-PK khususnya pada indikator hipertensi di Kabupaten Badung. Faktor - faktor yang mempengaruhi yaitu pola aktivitas masyarakat yang tinggi sehingga susah untuk bertemu warga saat melakukan kunjungan keluarga. Hasil ini sejalan dengan penelitian Adiartha, (2019) juga menyebutkan bahwa pola aktivitas penduduk yang tinggi mempengaruhi pelaksanaan program dari segi sosial budaya. Tradisi dan adat budaya tidak mempengaruhi pelaksanaan program. Walaupun ada upacara adat atau rahinan suci keagamaan, masyarakat tetap bisa melakukan pengobatan. Pihak petugas puskesmas dapat melakukan penjadwalan kegiatan ulang jika terbentur oleh upacara adat. Tradisi dan budaya secara tidak langsung akan mempengaruhi pola konsumsi masyarakat yang dapat menyebabkan hipertensi. Adanya jamuan rokok saat berlangsungnya hajatan juga akan mempengaruhi kejadian hipertensi, mengingat merokok adalah salah satu faktor risiko hipertensi. Selain itu setiap rangkaian upacara keagamaan menyuguhkan makanan tradisional Bali dari daging - dagingan yang mengandung lemak dan garam yang tinggi. Makin tinggi lemak mengakibatkan kadar kolesterol dalam darah meningkat yang akan mengendap dan menjadi plak yang menempel pada dinding arteri, plak Email Korespondensi : dayu.anggita@gmail.com tersebut menyebabkan penyempitan arteri sehingga memaksa jantung untuk bekerja lebih berat dan tekanan darah menjadi tinggi (Andria, 2013).

\section{SIMPULAN}

Simpulan penelitian ini adalah SDM yang bertanggung jawab untuk indikator hipertensi PIS-PK yaitu pemegang program hipertensi di puskesmas; tidak ada dana khusus untuk mendukung PISPK pada indikator hipertensi; Sarana prasarana pendukung berupa tensimeter, pinkesga dan alat tulis; metode berupa kunjungan keluarga; sasaran yaitu keluarga. Hambatan dari segi input yaitu beban kerja yang tinggi; pencairan dana untuk operasional program yang lambat dan tidak dianggarkannya dana untuk intervensi lanjutan hipertensi; permasalahan sarana saat intervensi awal; warga tidak dirumah saat dikunjungi, terjadi penolakan dan lemahnya kesadaran masyarakat untuk berobat teratur.

Proses perencanaan berupa pembuatan tim dan jadwal tindak lanjut; Implementasi dilakukan dengan kunjungan, posbindu dan program inovasi; Monev dilakukan 1 dan 3 bulan sekali melalui rapat minilok dan melakukan pelaporan via aplikasi KS dan laporan bulanan. Tidak ada kendala dari sisi perencanaan karena sudah diintegrasikannya PIS-PK dengan P1 puskesmas. Dari sisi implementasi hambatan disebabkan karena kurangnya petugas untuk intervensi lanjutan indikator hipertensi, fakta bahwa masih ada masyarakat yang belum mendapatkan 
intervensi dan definisi operasional indikator hipertensi yang ambigu

Lingkungan internal dan geografi tidak mempengaruhi program. Faktor ekonomi tidak mempengaruhi pelaksanaan program namun akan mempengaruhi gaya hidup masyarakat. Faktor sosial budaya mempengaruhi pelaksanaan program.

\section{SARAN}

Puskesmas sebaiknya meningkatkan kerjasama lintas program berupa penyelipan materi hipertensi pada penyuluhan programnya dan kerjasama lintas sektor seperti meminta bantuan kaling guna meningkatkan kesadaran masyarakat untuk melakukan pengobatan hipertensi secara teratur. Puskesmas dianjurkan untuk melakukan verifikasi data kembali, mengembangkan program inovasi yang ada, serta melakukan analisis SWOT untuk membantu meminimalisir hambatan yang terjadi.

Dinas kesehatan sebaiknya meningkatkan supervisi dan melakukan follow up rutin pada puskesmas dengan data capaian yang stagnant. Bagi peneliti selanjutnya yang tertarik meneliti tentang PIS-PK pada indikator hipertensi dapat mengembangkan topik penelitian ini dengan penelitian kuantitatif mengenai faktor-faktor yang mempengaruhi keteraturan meminum obat pada penderita hipertensi di Kabupaten Badung, guna membantu puskesmas atau dinas kesehatan melihat tren yang terjadi di masyarakat sehingga intervensi program padat dilaksanakan dengan tepat.

\section{DAFTAR PUSTAKA}

Adiartha, D. (2019). Hambatan Implementasi Program Indonesia Sehat Dengan Pendekatan Keluarga di Wilayah Kerja Puskesmas Kubu II Kabupaten Karangasem. Universitas Udayana.

Agni, M. (2018). 'Kesiapan Daerah Istimewa Yogyakarta dalam Penerapan Program Indonesia Sehat dengan Pendekatan Keluarga', Forum Ilmiah Kesmas Respati, 3(1), pp. 43-49.

Amirullah. (2015). Fungsi-ProsesPengendalian. Jakarta: Mitra Wacana Media.

Andria, K. (2013). 'Hubungan Antara Perilaku Olahraga, Stress, dan Pola Makan Dengan Tingkat Hipertensi Pada Lanjut Usia di Posyandu Lansia Kelurahan Gebang Putih Kecamatan Sukolilo Kota Surabaya', Promkes, 1(2), pp. 111-117.

Dewi, I., Salami \& Sajodin. (2017). 'Implementasi Fungsi Keluarga dan Self Care Behaviour Lanjut Usia Penderita Hipertensi', Keperawatan Aisyiyah, 4.

Ekarini, D. (2011). Faktor - Faktor yang Berhubungan dengan Tingkat Kepatuhan Klien Hipertensi dalam Menjalani Pengobatan di Puskesmas Gondangrejo Karanganyar, Keperawatan STIKES Kusuma Husada. Available at: jurnal.stikeskusumahusada.ac.id

(Accessed: 30 June 2020).

Ekowati, Shaluhiyah, Z. \& Agushybana, F. (2019). 'Pengaruh Pemanfaatan Aplikasi Keluarga Sehat terhadap Kinerja Petugas Promosi Kesehatan Puskesmas', Promosi Kesehatan Indonesia, 14(2), pp. 91-107.

Fauzan, A., Chotimah, I. \& Hidana, R. 
(2019). 'Implementasi Program Indonesia Sehat Dengan Pendekatan Keluarga (PIS-PK) Di Puskesmas Mulyaharja', Jurnal Mahasiswa Kesehatan Masyarakat, 2(3), pp. 172-181. Available at: http://ejournal.uikabogor.ac.id/index.php/PROMOTOR.

Gile, P., Samardzic, M. \& Klundert, J. (2018). 'The Effect of Human Resources Management on Performance in Hospital in SubSaharan Africa : a systematic literature review', Human Resources for Health, 16(1).

Kasmarani, M. (2012). 'Pengaruh Beban Kerja Fisik dan Mental Terhadap Stress Kerja Pada Perawat di Instalasi Gawat Darurat (IGD) RSUD Cianjur', Kesehatan Masyarakat, 1(2), pp. 767-776.

Kemenkes RI. (2014). Infodatin Hipertensi. Jakarta: Pusdatin Kemenkes RI.

Kemenkes RI. (2016a). Pedoman Umum Program Indonesia Sehat Dengan Pendekatan Keluarga. Jakarta: Kemenkes RI.

Kemenkes RI. (2016b). Peraturan Menteri Kesehatan No. 39 tahun 2016 tentang Program Indonesia Sehat Dengan Pendekatan Keluarga. Jakarta: Kemenkes RI.

Kemenkes RI. (2016d). Petunjuk teknis Penguatan Manajemen Puskesmas Dengan Pendekatan Keluarga. Jakarta: Kemenkes RI.

Kemenkes RI. (2017). Pedoman Monitoring dan Evaluasi Program Indonesia Sehat Dengan Pendekatan Keluarga (PIS-PK). Jakarta: Kemenkes RI.

Laelasari, E. et al. (2019). 'Model Intervensi Hipertensi di Puskesmas Purwoyoso, Semarang', Jurnal Ekologi Kesehatan,
18(1), pp. 15-26.

Laura, C. (2019). Pengaruh Stres Kerja dan Konflik Kerja Terhadap Kinerja Karyawan dengan Kepuasan Kerja Sebagai Variabel Intervening pada Puskesmas IV Koto Mudiak Pesisir Selatan. Universitas Putra Indonesia.

Matheos, B., Bidjuni, H. \& Rottie, J. (2018). 'Hubungan Peran Keluarga dalam Mengontrol Gaya Hidup Dengan Derajat Hipertensi di Puskesmas Tugulandang Kabupaten Sitaro', Keperawatan, 6(1).

Miyuslianu, A. \& Yunita, J. (2011). 'Fakto Risiko yang Berpengaruh terhadap Kepatuhan Diet Hipertensi', Kesehatan Komunitas, 1(3).

Munandar, M., Astuti, E. \& Hakam, M. (2014). 'Pengaruh Keselamatan, Kesehatan Kerja (K3) dan Insentif Terhadap Motivasi dan Kinerja Karyawan', Administrasi Bisnis, 9(1-9). Nia, D., Wahyuni, T. \& Sutriningsih, A. (2018). 'Tingkat Pengetahuan Lansia Tentang Penyakit Hipertensi Sebelum dan Sesudah Penyuluhan di Posyandu Lansia Permadi RW 02 Kelurahan Tlogomas Kecamatan Lowokwaru Malang', Nursing News, 3(3), pp. 522532.

Pratiwi, N., Malisan, L. \& Lahaya, I. (2017). 'Pengaruh Regulasi dan Ketersediaan Anggaran Terhadap Kualias Pelayanan Kesehatan', Ilmu Akutansi Mulawarman, 2(3).

Purnamaningrum, A. (2010). Faktor - Faktor yang Berhubungan Dengan Perilaku Masyarakat Untuk Mendapatkan Pelayanan Kesehatan Mata, Universitas Diponogoro. Available at: http://eprints.undip.ac.id/23137/1/Ayu 
_P.pdf (Accessed: 1 July 2020).

Sarda, A. (2018). 'Pengaruh

Kepemimpinan, Beban Kerja dan

Kondisi Kerja terhadap Stress Perawat

di UPTD Kesehatan Puskesmas

Palanro Kecamatan Mallusetasi

Kabupaten Barru', Journal of

Management, 1(3), pp. 1-10.

Setyawati, L. (2010). Sekilas tentang

Kelelahan Kerja. Yogyakarta: Amara

Books.

Sitepu, A. (2013). 'Beban Kerja dan

Motivasi Pengaruhnya Terhadap

Kinerja Karyawan Pada PT. Bank

Tabungan Negara Tbk Cabang Manado', EMBA, 1(4), pp. 1123-1133.

Virdasari, E., Arso, S. \& Fatmasari, E.

(2018). 'Analisis Kegiatan Pendataan
Keluarga Program Indonesia Sehat dengan Pendekatan keluarga di Puskesmas Kota Semarang (Studi Kasus pada Puskesmas Mijen)', Kesehatan Masyarakat, 6(5), pp. 52-65.

Wahyudi, C., Ratnawati, D. \& Made, S. (2017). 'Pengaruh Demografi, Psikososial dan Lama Menderita Hipertensi Primer Terhadap Kepatuhan Minum obta Antihipertensi', JKFT, 2, pp. 14-28.

Widiyartha, J., Putra, A. \& Ani, S. (2016). 'Riwayat Keluarga, Stres, Aktivitas Fisik Ringan, Obesitas dan Konsumsi Makanan Asin Berlebihan Sebagai Faktor Risiko Hipertensi', Public Health and Preventive Medicine archieve, 4(2), pp. 184-194. 